\title{
Correction to: The structural relationship between organizational justice and organizational citizenship behavior in university faculty in China: the mediating effect of organizational commitment
}

\author{
Zhao Donglong $^{1} \cdot$ Cho Taejun $^{2}$ (D) Ahn Julie ${ }^{3} \cdot$ Lee Sanghun $^{4}$
}

Published online: 14 November 2019

(c) Education Research Institute, Seoul National University, Seoul, Korea 2019

\section{Correction to: Asia Pacific Education Review https://doi.org/10.1007/s12564-019-09617-w}

In the original publication of the article, the Acknowledgements section was missed and it has been included in this Correction.

Acknowledgements This work was supported by the Incheon National University (No. 20151768).
Publisher's Note Springer Nature remains neutral with regard to jurisdictional claims in published maps and institutional affiliations.

The original article can be found online at https://doi.org/10.1007/ s12564-019-09617-w.

Cho Taejun

chotaejun@inu.ac.kr

Zhao Donglong

zhaodonglong@126.com

Ahn Julie

julieahn@cau.ac.kr

Lee Sanghun

1sh85@snu.ac.kr

1 Department of Business Administration, LinYi University,

Shuangling Road, Lanshan District, LinYi City,

Shandong Province 276000, China

2 Department of Creative Human Resource Development, Incheon National University, 119 Academy-ro 13-302,

Yeonsu-gu, Incheon 406-772, Korea

3 Da Vinci College of General Education, Chung-Ang University, Heukseok-ro 84 Building 303-804, Dongjak-gu, Seoul 06974, Korea

4 Department of Education, College of Education,

Seoul National University, 1 Gwanak-ro, Gwankak-gu,

Seoul 08826, Korea 